\title{
Emociones como juicios de valor en las tramas de los planes de vida de jóvenes universitarios*
}

\author{
[Artículos]
}

\author{
María Elvia Domínguez Blanco ** \\ Fecha de entrega: 26 de agosto de 2020 \\ Fecha de evaluación: 30 de octubre de 2020 \\ Fecha de aprobación: 15 de noviembre de 2020 \\ los planes de vida de jóvenes universitarios. Cuadernos de Filosofía \\ Latinoamericana, 42(124). https://doi.org/10.15332/25005375.6099
}

Citar como:

Domínguez Blanco, M. E. (2021). Emociones como juicios de valor en las tramas de

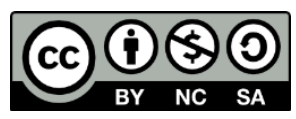

\section{Resumen}

Esta investigación busca comprender el sustrato emocional en los planes de vida de los jóvenes universitarios, en cuanto a sus juicios de valor sobre una vida digna y buena en situaciones de vulnerabilidad, así como la intencionalidad y los modos de comunicación de estos en la

\footnotetext{
* Artículo de investigación que presenta resultados originales de la tesis "Emociones morales como tramas narrativas de planes de vida de jóvenes universitarios", dirigida por la profesora Marieta Quintero Mejia (Ph. D.), para obtener el título de doctora en Educación, Colombia. Agradecimientos a las profesoras Liliana Molina y Claudia Patricia Fonnegra, y al profesor Hernán Alonso Jaramillo, de la línea "Emociones, narrativas y política" del doctorado del Instituto de Filosofía de la Universidad de Antioquia. Además, a Vanessa Zambrano, estudiante auxiliar de la Cátedra "Emociones morales y políticas en la experiencia universitaria (2018-03)", así como a las y los estudiantes que participaron en ella, especialmente a quienes aportaron sus planes de vida para este estudio.

** Docente del Departamento de Psicología de la Universidad Nacional de Colombia.
} 
experiencia universitaria. A partir de la propuesta investigativa hermenéutica narrativa de Quintero-Mejía (2019), se interpretaron las emociones morales presentes en las tramas de planes de vida de los estudiantes de la Universidad Nacional de Colombia. El autoexamen reveló los conflictos emocionales sobre las situaciones vulnerables que escaparon al control, y los juicios reconstructivos mostraron cómo el miedo, la culpa, la vergüenza o la humillación afectaron el equilibrio emocional. Además, cada estudiante mostró, los juicios compromisorios para el bien propio (florecimiento personal) y creencias hacia el bien común (justicia).

Palabras clave: emociones, estudiantes universitarios, juicios de valor, tramas narrativas, planes de vida.

\section{Emotions as value judgments in the plots of young university students' life plans.}

\section{Abstract}

This research seeks to understand the emotional substrate in the life plans of young university students, in terms of their value judgments about a dignified and good life in situations of vulnerability, as well as the intentionality and forms of communication of these in the university experience. Based on the narrative hermeneutic research proposal by Quintero-Mejia (2019), the moral emotions in the life plans plots of students from the Universidad Nacional de Colombia were interpreted. Self-examination revealed emotional conflicts about vulnerable situations that were beyond control, and reconstructive judgments showed how fear, guilt, shame or humiliation affected emotional balance. In addition, each student showed compromising judgments for their own sake (personal flourishing) and beliefs towards the common good (justice).

Keywords: emotions, university students, value judgments, narrative plots, life plans. 
The planned life can be viewed as the contemporary counterpart of the ancient theoretical idea of examined life. Both are attempts to articulate the sources of life's meaning. Like the unexamined life, an unplanned life is a wasted life. DAVID HEYD Y FRANKLIN G. MILLER, "Life plans: do they give meaning to our lives?”

\section{Introducción}

Esta investigación busca comprender el lugar de las emociones como juicios de valor en tramas de planes de vida de los jóvenes universitarios de la Universidad Nacional de Colombia, sede Bogotá. Con el objeto de mostrar cómo las aspiraciones a una vida buena y digna son elementos vulnerables de la experiencia humana. Con este modo de reflexión ética, se espera contribuir a la formación de una conciencia emocional para el planeamiento de una vida, al entender tanto a la búsqueda de la satisfacción de necesidades, como al bien común. En palabras de Nussbaum (2004), las emociones como pensamientos evaluativos "deben ayudar a comprender la indeterminación, la complejidad y la dificultad para la deliberación humana” (p. 43).

Según esta filosofa, la educación universitaria en torno a la rentabilidad ha producido una falta de autoconciencia en cuanto a los objetivos de una vida buena y digna para sí y para otros. Estos criterios morales deben orientar una vida verdaderamente humana, la cual debe ser examinada para tomar decisiones acerca de lo que "uno quiere y le importa" (Nussbaum, 2014, p. 77). La investigación sobre los planes de vida 
estudiantiles puede contribuir a revisar criticamente las metas y los objetivos en los proyectos profesionales.

En los planes de vida, las emociones otorgan relevancia a los compromisos con objetos, personas o situaciones y los convierten en valiosos por sí mismos. Es decir, las emociones conducen a las valoraciones constitutivas de la propia vida en la experiencia estudiantil. Las emociones, como juicios de valor, conciernen a juicios prácticos sobre los valores que entran en conflicto en la experiencia humana, es decir, estos juicios están afectados por eventos del mundo que se hallan por fuera del control de cada persona (bienes externos, relaciones afectivas o laborales). Según Nussbaum (2004) un plan de vida no es completamente racional ni lineal, debido a que las elecciones morales están afectadas por la fragilidad de la experiencia humana. En estas elecciones, las emociones anticipan situaciones placenteras o dañinas. El amor, la compasión y el miedo son las principales emociones que contribuyen o frenan acciones validas en la planeación de una vida.

De acuerdo a lo anterior, esta investigación indagó ¿̇cómo afectan las emociones las tramas de los planes de vida en la experiencia universitaria de los jóvenes? Esta pregunta condujo a interpretar el sustrato emocional presente en aspiraciones a una vida buena y digna en la fragilidad de la condición estudiantil. Esta exploración adquiere mayor sentido en un ciclo histórico marcado por la inestabilidad y la incertidumbre debido a nuevas desigualdades para las instituciones de educación superior.

La indagación sobre planes de vida se inscribe en el campo de la experiencia universitaria para dar cuenta, según Carli (2012), de las prácticas cotidianas y la reflexión sobre ellas en las diferentes temporalidades. En este marco epistemológico la experiencia estudiantil emergió para superponer temporalidades en movimiento cargadas de 
símbolos, signos y afectos. Esta expresión implicó construir un puente entre el lenguaje de lo público y la interioridad de cada estudiante. Por esto, fue preciso apoyarse en el giro biográfico y otorgar un lugar discursivo a la "dimensión literaria del lenguaje y lo autobiográfico, como zona explorada principalmente por el feminismo" (Carli, 2012, p. 31). A partir de lo anterior, esta investigación propone que la experiencia estudiantil pueda enriquecerse con los aportes de la filosofía práctica, para acercarse a los planes de vida y atender al carácter afectivo -emociones-, sin perder de vista el devenir histórico en el cual discurre la experiencia universitaria. El plan de vida como una trama narrativa revela las emociones en los conflictos morales y contribuye a examinar su vínculo con otras esferas de la experiencia en las trayectorias académicas. Específicamente, Martha C. Nussbaum (2012), ofrece una perspectiva compleja, pero iluminadora, del razonamiento moral para humanizar los planes de vida estudiantiles. Esta filósofa llevó a cabo un análisis sistemático del bienestar desde el enfoque de las capacidades centrales, en combinación con el análisis de las experiencias morales, donde las emociones hacen parte de la racionalidad pública. A su vez, su proyecto filosófico contiene una explicitación del bien y de la dignidad como fundamentos del bienestar individual y de las políticas públicas.

Nussbaum (2012) ha promovido un tratamiento terapéutico de las emociones a través de la deliberación práctica, siguiendo a las escuelas helénicas. En la terapia del deseo, ella demostró que estas escuelas practicaron diversos modos de la analogía médica, según la cual cada persona puede examinar la correspondencia entre sus deseos y creencias. Ello implicaba incluir las emociones en el planeamiento de una vida cumplida para sacar a la luz tensiones y prevenir contingencias futuras. Esta investigación adoptó la deliberación desiderativa para mostrar el vínculo entre las emociones y las narrativas de un plan de vida, el cual 
exige una voz propia que dé unidad a lo heterogéneo de la experiencia estudiantil, en cuanto a deseos, pensamientos, momentos y procesos de cualquier tipo que se pueden, efectivamente, encontrar su estructura temporal en un trama narrativa.

El autoexamen tuvo como propósito terapéutico deliberar sobre consecuencias deseadas y no deseadas en conflictos morales presentes en situaciones de vulnerabilidad. Las autoevaluaciones permitieron desentrañar el confuso material cognitivo de las emociones que vinculó objetos inestables como necesidades, deseos y aspiraciones para dar cuenta de los criterios normativos para una vida digna de ser vivida.

Desde este horizonte hermenéutico, las tramas de planes de vida de los jóvenes universitarios son imitaciones creadoras de actos retrospectivos que captan o develan la responsabilidad moral en sus acciones, con el fin de ganar conciencia de las elecciones en tiempo presente. Por esto, su estructura narrativa configura una puesta en intriga por la disposición y combinación de acontecimientos que la convierten en una historia con comienzo, nudo y resolución. Según Nussbaum (2004), el desenlace representa un final cuando el nudo se desata, porque el personaje reconoce su acción (anagnórisis), o se produce un daño para sí o para otras personas (lance patético). Y según Ricoeur (2004), la trama narrativa compone los hechos como poésis en cuanto a la selección y disposición de los acontecimientos.

Los planes de vida como tramas narrativas fueron sistematizados e interpretados desde la propuesta de investigación hermenéutica narrativa (PIHN), desarrollada por Quintero-Mejía (2019) a partir de la triple mímesis de Ricoeur (2004). Como se afirmó anteriormente, este filósofo propuso comprender la experiencia humana como narración de acciones puestas en una intriga que vincula las emociones con la concordancia- 
discordancia de una trama narrativa. La estructura de una trama narrativa puede ser comprendida como mímesis creadora en tres tiempos: preconfiguración (antes), configuración (durante) y reconfiguración (después).

Este artículo presenta los conceptos y resultados de la estructura temporal de tres tramas narrativas en cuatro niveles: el registro de codificación, el textual, el contextual y el meta-textuales. El nivel 1 identificó cada trama narrativa, según las características de cada estudiante. El nivel 2 describió las acciones, en cuanto a fines de vida buena y digna, consecuencias deseadas y no deseadas, temporalidades y espacialidades. El nivel 3 destacó la contribución de las fuerzas narrativas que otorgaron valor moral a las acciones de sujetos de enunciación, como agentes morales competentes. El nivel 4 llevó a cabo la reconfiguración de las tramas narrativas trágicas de planes de vida en cuanto a los conflictos emocionales entre valores vulnerables para el florecimiento humano en la contingencia de la experiencia estudiantil.

\section{Emociones como juicios de valor en planes de vida}

\section{Los planes de vida}

El plan de vida fue importante para el liberalismo, porque contribuyó a fundamentar la construcción del individuo con libertad y racionalidad. Específicamente, aportó una visión moderna prescriptiva al definir que las elecciones en un plan de vida son sociales y se vinculan a principios de una vida buena. John S. Mill (1801-1873) y John Rawls (1921-2002) consideraron que un plan de vida incluía creencias morales que van más allá de los emprendimientos personales y de los fines de una sociedad. Porque un plan de vida abarca la reflexión ética acerca de aquellas experiencias y de aquellos logros que son considerados verdaderamente 
humanos. Para la filosofía práctica contemporánea, estas obligaciones morales se trasladaron al campo de la realización ética, la cual "retornó a las preguntas de las escuelas helénicas acerca de qué vida deberíamos llevar y qué define una vida bien vivida más allá de nuestras preferencias individuales" (Appiah, 2007, p. 20). En esta indagación, según Pinedo y Yáñez (2018), las pasiones contribuían a revelar qué tipo de vida se debía llevar para alcanzar la eudaimonia o felicidad (p. 19-20).

A partir del estudio de las tragedias griegas, Martha C. Nussbaum (2004) interrogó cómo afectan el bien humano a aquellos elementos que no dependen del agente moral. Ella los llamó fortuna, según Aristóteles en la Ética a Nicómaco. También interrogó cómo la fortuna, junto a otros bienes como la amistad, el amor y la actividad política ¿̇se podrían incluir como componentes racionales de un plan de vida? Esta filosofa consideró que los componentes de la excelencia humana van más allá de los límites cognitivos del ser humano, porque lo bueno tiene una estabilidad relativa y no es inmune a la fortuna; como tampoco a una meta subordinada a lo que se considera valioso. Si bien para esta autora las emociones han sido consideradas elementos ingobernables de la personalidad, estas contribuyen a la deliberación moral porque permiten enlazar objetos perecederos, debido a la perdida, los conflictos y otras contingencias. No obstante lo anterior, la planeación de una vida sin vínculo con la fortuna y las emociones también estaría empobrecida:

[...] las emociones son elementos constitutivos de una vida buena, porque ligan al agente a eventos no controlados, porque envuelven juicios que le dan valor a lo que está por fuera de nosotros, que no se puede controlar, y que da cuenta del vínculo con lo externo: las emociones nos hacen vulnerables. (Nussbaum, 2004, p. 6)

Cuadernos de Filosofía Latinoamericana ISSN: 0120-8462 | e-ISSN: 2500-5375 | DOI: https://doi.org/10.15332/25005375 Vol. 42 N.o 124 | enero-junio de 2021 
Nussbaum (2004) criticó la racionalidad en la planeación de una vida buena, al considerar que sus elementos constitutivos vinculan, en primera instancia, el papel de las actividades y relaciones que son vulnerables a la adversidad, los cuales están abiertas al azar, no son instrumentales, sino que se convierten en valores eudaimónicos o fines para la excelencia humana. En segundo lugar, la relación entre los anteriores fines puede ser armoniosa o conflictiva. En este caso, se adoptan estrategias para minimizar el conflicto o disminuir la fragilidad entre valores. Si un agente moral otorga un valor intrínseco a más de una actividad, hay riesgo de que genere incompatibilidad en el curso de una acción.

\section{Las emociones como juicios de valor}

Para Martha C. Nussbaum (2004), las emociones contribuyen a una evaluación eudaimonista que vincula el sentido del yo a los "fines y objetivos, a las cosas que asignamos valor en el marco de una concepción de lo que significa vivir bien, independientemente de lo bien o mal que tales elementos puedan ensamblar" (Nussbaum, 2018, pp. 71-72). Ella señaló algunas características para el estudio de su valor hermenéutico: Las emociones dan cuenta de objetos, personas o situaciones que, en los planes de vida, permiten interpretar los objetivos o los logros que tienen importancia para las y los jóvenes, quienes consideran que su alcance es bueno o digno para todos los seres humanos (juicios eudaimonistas). Las emociones son acerca de algo, por lo tanto, expresan creencias e intencionalidades (referencia interna). Si las emociones ocurren por o para algo, el carácter hermenéutico está en interpretar en planes de vida, los objetos o las situaciones que producen vulnerabilidad (referencia externa), para ponderar medios para alcanzar fines para una vida bien vivida. 
Las emociones como pensamientos evaluativos se comunican en deliberaciones, en cuyas tramas narrativas se encuentra lo que afecta positiva o negativamente los objetivos, y representan el mundo desde la perspectiva de dichos objetivos y proyectos. Siguiendo a Crisipo de Solos (281 a 208 a. c.), Nussbaum (2012) afirmó que estas apariencias tienen un contenido proposicional que se expresa lingüísticamente, como juicio de valor. Es decir, lo que se enuncia como un estado de cosas corresponde a una traducción verbal del episodio emocional (Nussbaum, 2012). Desde esta perspectiva, la emoción se experimenta como un juicio sobre un asentimiento como actos voluntario de lo que se acepta o rechaza con firmeza, y que se integra a la conciencia intencional.

1. Estipulan lo que el agente moral dota de valor o lo contrario. Las emociones son acerca de lo bueno y lo malo, lo meritorio y lo no meritorio, favorable o perjudicial.

2. Asignan al objeto una valoración extrema: elevada o disminuida (movimiento o levantamiento/inclinación del pensamiento): el objeto es sobrevalorado es subvalorado.

3. Descansan "sobre creencias que tienen en común otorgar un alto valor a bienes externos vulnerables: objetos que escapan al control de agentes morales, objetos que pueden verse afectados con lo que ocurre en el mundo" (Nussbaum, 2012, p. 460).

Por ende, las emociones como los juicios de valor son pensamientos evaluativos "que producen efectos psicológicos como la excitación y que Proust llamó levantamiento experiencia de agitación o conmoción" (Nussbaum, 2018, p. 85), como ondulaciones de la experiencia que albergan temporalmente juicios prácticos que se convierten en disposiciones para deliberar sobre algo digno de ser vivido. Es decir, producen sensaciones corporales (Ahmed, 2015) como experiencias de 
agitación, conmoción o excitación que Nussbaum (2018) denominó

"levantamiento geológicos del pensar" (p. 111).

Las características del contenido proposicional de las emociones como los juicios de valor se sintetizan en la siguiente figura (ver figura 1)

(Nussbaum, 2012, pp. 467-469).

\section{Figura 1.}

Los juicios de valor como presuposiciones valorativas equivalentes a emociones según Crisipo de Solos.

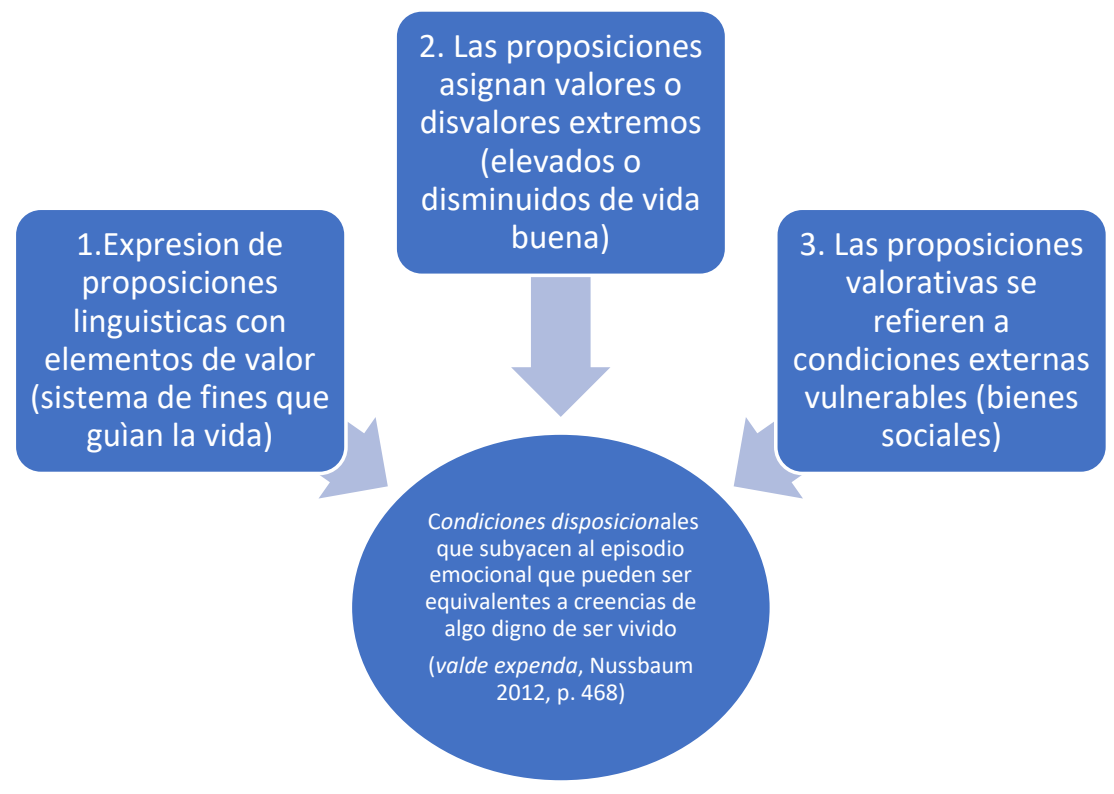

Fuente: elaboración propia a partir de información en Nussbaum (2012, pp. 467-469).

Las condiciones disposicionales de cada agente moral durante el episodio emocional hacen referencia a las capacidades combinadas. Es decir, las capacidades básicas con las cuales ha sido dotado más las capacidades centrales de una sociedad que aspira a la igualdad. Nussbaum (2002) propuso diez capacidades centrales que corresponden a aspiraciones para una vida digna de ser vivida, las cuales hacen parte de los planes de vida, porque constituyen preocupaciones legítimas a alcanzar en la vida con y 
para otros ${ }^{1}$. Sobre todo, cuando esta se encuentre por debajo del umbral mínimo de sobrevivencia, lo cual implica que han sido vulnerados los derechos fundamentales.

De acuerdo a lo anterior, para Martha C. Nussbaum (2002) un plan de vida condensa los fines para alcanzar una vida digna y buena: lo que un ser humano es capaz de hacer y ser por sí mismo y para los demás. Es decir, desarrollar capacidades combinadas para el florecimiento personal y el bien común. Para esta autora, toda persona es un fin en sí mismo y, por lo tanto, sus objetivos y sus proyectos deben ser considerados con todo respeto. En consecuencia, las instituciones deben garantizar que estas aspiraciones estén protegidas como derechos fundamentales.

\section{Emociones en la deliberación de planes de vida como tramas narrativas}

En un plan de vida las emociones como los pensamientos evaluativos contribuyen a fijar criterios acerca de lo que se considera valioso para una vida cumplida como objetos, eventos o personas. En la deliberación contribuyen a una techne orientadora de las elecciones, porque permiten anticipar el futuro a partir de la aprehensión organizada del pasado, para así ganar consciencia de la naturaleza y de la relación entre obligaciones morales (Nussbaum, 2004). A su vez, los planes de vida como las tramas narrativas, siguiendo a Ricoeur (2004), reportan el obrar y el sufrir como síntesis de diversos elementos heterogéneos: acontecimientos, temporalidades, espacialidades y fuerzas narrativas; los cuales están teñidos de emociones cuya carga semántica y pragmática orienta el curso de una vida digna de ser vivida.

\footnotetext{
${ }^{1}$ Las capacidades humanas centrales son vida, salud corporal, integridad corporal, sentidos, imaginación y pensamiento; emociones, razón práctica, afiliación, otras especies, juego y control sobre el propio entorno.
}

Cuadernos de Filosofía Latinoamericana

ISSN: 0120-8462 | e-ISSN: 2500-5375 | DOI: https://doi.org/10.15332/25005375

Vol. 42 N. 0124 | enero-junio de 2021 
Los planes de vida se estructuran a partir de una prospección intencional de la acción. Esto implica que deben ser juzgados comparando la situación actual, con lo que ocurrió en el pasado. Esta evaluación pondera tanto los acontecimientos planeados como los inesperados. El criterio de comparación corresponde a una interpretación de lo bueno que incluye tanto los compromisos para la realización del plan, como otras circunstancias favorables o desfavorables. De tal manera que la vida es examinada como relato que contiene los juicios morales que le dan significado a acciones pasadas, presentes y futuras acompañadas de "sentimientos de confusión o excitación" localizadas siempre en un cuerpo (Nussbaum, 2018).

Según Heyd y Miller (2010) la comprensión retrospectiva del significado de una vida se lleva a cabo por medio de una narrativa, la cual orienta el horizonte de sentido a partir de la iluminación del pasado. Para estos autores, el plan de vida posee una estructura semejante a una narrativa de ficción, en la medida en que la historia es contada desde una perspectiva retrospectiva. Los acontecimientos son seleccionados para darle inteligibilidad a la experiencia y la personalidad de quien narra. La evaluación de los hechos tiene un valor moral y estético. Pero, en un plan de vida, esta evaluación guarda cierta independencia de las contingencias, y preserva los juicios de valor de lo que se considera una vida digna de ser vivida.

Para Ricoeur (2004), el tiempo propio de la narración y la historia es el tiempo que el relato genera por medio de la construcción original de la trama. Es el tiempo verdaderamente humano que aparece como competencia para seguir un relato desde el pasado, pasando por el presente, hacia el futuro como "flecha del tiempo" (Ricoeur, 2004, p. 130). Para este filósofo una trama debe interpretarse como una sucesión de hechos en una historia narrada: "la narración es la condición 
identificadora de la experiencia temporal porque la determina, la articula y la clarifica como tal" (p. 26). La narración permite llegar a la comprensión de los aspectos de la experiencia temporal. Esta temporalidad es un signo de contradicción y de aporía para la reflexión. Así, la narración identifica al sujeto en un ámbito eminentemente práctico, el del relato de sus actos. Sin narración no hay identificación subjetiva. También para Ricoeur (2004), el conocimiento de si corresponde a una vida examinada, contada y revisada por la deliberación.

La trama es la operación mediadora a través de la cual los acontecimientos adquieren la categoría de narración. En primer lugar, configura la historia como una totalidad, en la cual la construcción de la trama extrae la configuración de la sucesión de acontecimientos. En segundo lugar, la trama es una síntesis de lo heterogéneo, porque integra elementos dispares como agentes, fines, medios y circunstancias no esperadas. En tercer lugar, la trama incluye los incidentes que producen compasión y miedo en el espectador. Es decir, compone en una unidad dramática las acciones de personajes nobles y viles, que cometieron acciones validas o dañinas. Estos incidentes ocurren en coordenadas cronológicas y no cronológicas (comienzo, medio y final). Aristóteles en La poética, equiparó la trama a la configuración, Ricoeur (2004) a la concordancia-discordanciaomo operación mediadora que da cuenta de cambios en el obrar y el sufrir en la experiencia humana.

La trama hace verosímiles los incidentes de compasión y miedo vinculados al cambio de fortuna como incidentes discordantes. Esta inclusión en la concordancia de la trama significa incluir lo conmovedor en la inteligibilidad de la misma. Las operaciones que vinculan las emociones a la trama son la peripecia, la anagnórisis y los lances trágicos. La peripecia o intriga es la que permite vincular los acontecimiento a la historia como un todo; la anagnórisis da cuenta de incidentes que colocaron en situación 
vulnerable a los protagonistas; y las lances trágicos son los efectos violentos que contribuyeron a una acción dramática reforzada.

La compasión y el miedo ayudan a discernir las consecuencias de lo trágico en la configuración de la trama. Este discernimiento práctico otorga comprensión de las acciones de los protagonistas. Esta reflexión ética da cuenta de los juicios de valor retrospectivos sobre las circunstancias que rodearon las acciones, y las consecuencias no deseadas que forman parte de lo trágico. La composición de la trama muestra el obrar y el padecer, en circunstancias donde las y los protagonistas son agentes y víctimas. Es decir, da cuenta de la cualidad emocional de los incidentes en la vida de las personas.

Nussbaum (2002) analizó el lugar de la fortuna en el pensamiento ético de los poetas trágicos, no en relación con la bondad del carácter como lo propuso Aristóteles, sino del bien humano entendido como eudaimonia, como bien supremo para los demás, vinculados a fines y proyectos. Las acciones que se desarrollan a partir de un plan de vida no son solo medios, sino también sus partes constitutivas como fines morales. Esto supone incluirlas como elementos vulnerables, sensibles al cambio en un plan de vida, de seres necesitados de otras personas. Para ella, la amistad, el amor, la actividad política, el apego a los bienes primarios son elementos vulnerables y "exponen a los avatares de la fortuna a quienes se fíen en ellos" (Nussbaum, 2004, p. 28).

Finalmente, las emociones como reveladores cognitivos-afectivos contribuyen a tomar decisiones en los conflictos morales personales y colectivos, de modo que la katharsis cumpla una función mediadora entre la fragilidad de la experiencia y la racionalidad de los valores para el florecimiento. Asimismo, las emociones como los juicios de valor dan cuenta de las preferencias personales y de las aspiraciones públicas, 
orientadas a la búsqueda de la igualdad. En los planes de vida cada estudiante se convierte en narrador(a) compasivo(a) que delibera sobre el carácter bueno y las contingencias que discurren en su experiencia universitaria, lo que contribuye a evitar que sus elecciones trágicas representen daños irreparables para la sociedad y para sí mismo(a).

\section{Metodología}

El enfoque hermenéutico permitió desplegar el horizonte vital de los planes de vida de los jóvenes, a partir de la deliberación moral de su experiencia en el devenir universitario. Entendida esta como el modo o los modos en que las personas observan e interpretan el mundo en elecciones prácticas que se designan en el uso del lenguaje. De acuerdo con Ricoeur (2000), el atributo común de la experiencia humana "es el acto de narrar en todas sus formas adoptando un carácter temporal, marcado y articulado" (p. 16 [cursiva en el original]). Todo lo que se cuente sucede en el tiempo y, solo desde allí, pueden narrarse las acciones que corresponden a una "historia que ella misma inaugura" (Ricoeur, 2004, p. 4). Por tanto, las acciones no son ni medios ni fines para narrar. Ellas provocan un cambio en la fortuna. Deshacen una intriga en resultados sorprendentes, donde cada joven se reconoce en el desenlace que afectó su vida con y para otras personas. Esto contribuye a orientar la razonabilidad en las expectativas futuras en planes de vida, para calibrar metas personales con necesidades colectivas, según las consecuencias de acciones pasadas.

\section{Sujetos de enunciación}

La investigación se llevó a cabo en la asignatura Catedra Emociones Morales y Políticas en la experiencia universitaria en el 2018-03. Fue diseñada con la tutora de investigación con el objeto de desarrollar los fundamentos teóricos y prácticos para ampliar el horizonte hermenéutico 
de los proyectos de vida de los estudiantes de pregrado de la Universidad Nacional de Colombia, sede Bogotá.

Este estudio fue desarrollado con tres sujetos de enunciación de las

facultades de Ciencias Humanas, Ciencias Económicas y Ciencias, respectivamente:

Trama narrativa 1: “¿por qué lucho?”, estudiante masculino del Programa Especial de Admisión y Movilidad Académica (Peama), sede Arauca.

Trama narrativa 2: "encontrando una vida buena", estudiante femenina de admisión regular.

Trama narrativa 3: "crecí creyendo que no tenía nada que ofrecer a los demás", estudiante masculino de admisión regular.

Aspectos éticos: el curso fue informado de los objetivos investigativos para el desarrollo de las actividades pedagógicas de imitación creadora. El uso de la información obtuvo consentimiento informado individual.

\section{Estrategia de recolección de información}

La técnica cualitativa de recolección de información se denominó técnica imitativa creativa. Esta técnica está orientada a dar cuenta "de tránsitos o momentos en el curso de una vida que presentan contrastes o contradicciones, ambigüedades o inconsistencias en los procesos de planeamiento o auto-construcción vital" (Silver, 2013, p 442). Como ya se dijo, las composiciones verbales escritas dieron cuenta de tres tramas narrativas de conflictos morales prácticos o trágicos en la experiencia estudiantil. Los primeros incluyeron conflictos entre compromisos morales y aspiraciones para una vida buena y digna, donde emociones como la compasión y el temor pueden ser inteligibles. Los segundos contemplaron capacidades vulneradas, las cuales dieron lugar a lances trágicos (Aristóteles, 1948) por falta de compasión en individuos e 
instituciones. Con estas tramas narrativas, se esperaba que cada estudiante reconociera el lugar de las emociones en juicios morales que conllevaron a su propio florecimiento (Nussbaum, 2018).

\section{Tabla 1.}

Estrategia de recolección de información

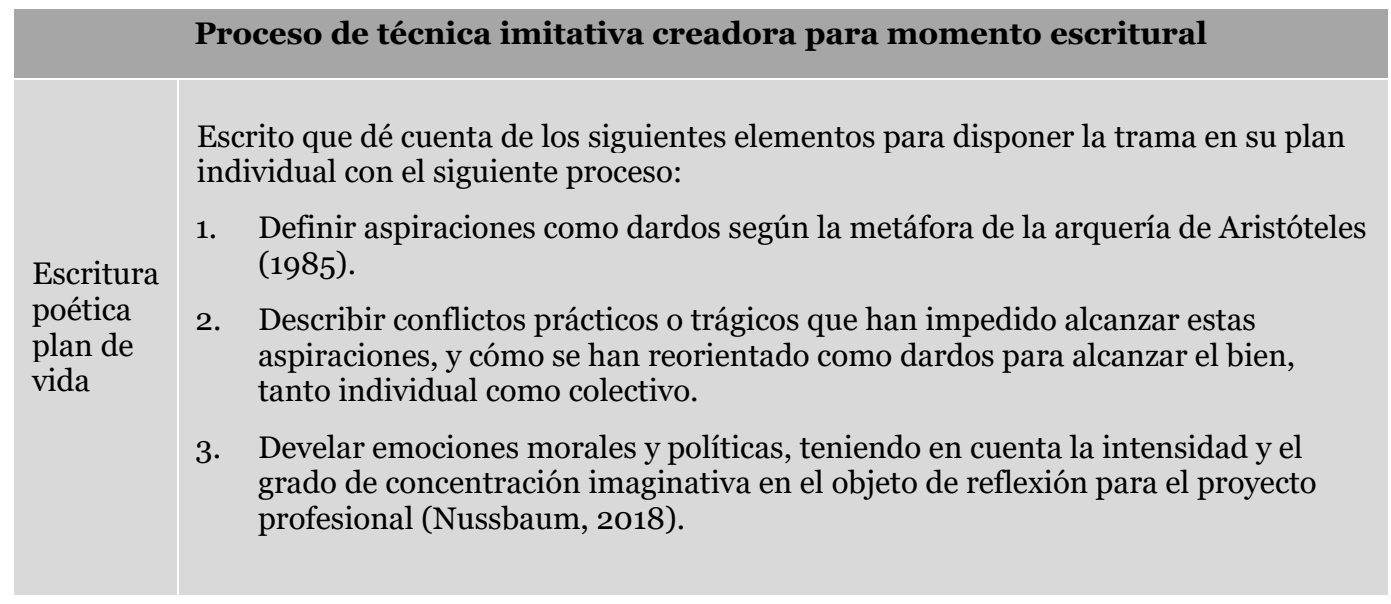

Fuente: elaboración propia.

Los planes de vida como las tramas pudieron ser sistematizados, comprendidos e interpretados a partir de los relatos obtenidos por la guía de autoexamen sobre conflictos morales en plan de vida buena y digna. En la tabla anterior (ver tabla 1) aparece diferenciado el proceso para la técnica imitativa en la guía de deliberación moral.

\section{Sistematización e interpretación de tramas narrativas}

Se inicia con la matriz 1 al numerar las líneas del texto y asignar códigos según: \# (número de la narrativa); M (sexo femenino), H (sexo masculino); Admisión R (regular) y Admisión E (especial)² y programa curricular (Letra inicial). Posteriormente, se llevaron a cabo quince

\footnotetext{
2 Programa Especial de Admisión y Movilidad Académica (Peama), en las sedes Amazonia, Caribe, Orinoquia, Tumaco y sede la Paz.
} 
matrices con la descripción e interpretación de cada trama narrativa para los niveles (Quintero-Mejía, 2019):

1. Momento II. Nivel textual. Preconfiguración. Se realizó la interpretación de las emociones en los acontecimientos en cuanto a temporalidades (tiempo de la experiencia vivida) y espacialidades (puntos de apoyo) en una trama narrativa. Implica dar cuenta del efecto de adherencia de las emociones a las aspiraciones para comprender cómo se crean los lazos intensos entre objetos y sujetos para el bienestar individual y colectivo.

2. Momento III. Nivel contextual y comunicativo. Configuración. Comprendió el análisis de las fuerzas narrativas y los atributos morales de los sujetos a partir de los tipos de acontecimientos en cada trama narrativa. Estos atributos configuran los fines de la deliberación moral y otorgan a cada sujeto de enunciación las capacidades de hacer, poder-hacer y saber-poder-hacer (Ricoeur, 2004, citado en Quintero-Mejía, 2019).

3. Momento IV. Nivel IV. Reconfiguración. Interpretación del lugar de las emociones presentes en los juicios de valor en diferentes temporalidades de las tramas narrativas, en cuanto a sus mecanismos de intensificación y afectación en la planeación de la vida de jóvenes universitarios.

\section{Resultados}

Puede afirmarse, que la deliberación con emociones vinculadas a los juicios de valor tendió un puente hacia la reflexión ética sobre la experiencia universitaria. Siguiendo a Martha C. Nussbaum (2004) el núcleo central de esta reflexión fue el vínculo de la vida buena (subjetiva) con la vida digna (reciprocidad intersubjetiva). Primero, las emociones vincularon bienes relacionales como la familia, la comunidad y la vida al 
proyecto de obtener un título profesional como juicios aspiracionales. Con estos juicios prácticos cada estudiante sometió a escrutinio sus condiciones disposicionales como obstáculos u oportunidades para que la vida se preserve como buena, en cuanto a la limitación de las capacidades centrales como ejercicio de libertades fundamentales para acciones valiosas. Los juicios de valor aspiracionales como presuposiciones valorativas estuvieron presentes en el nivel de preconfiguración de la trama como acontecimientos con consecuencias deseadas y no deseadas en la dimensión prospectiva de los planes de vida (modo presente del futuro). Los juicios reconstructivos hicieron emerger a la superficie textual las partes más íntimas del sí mismo para ser examinadas en el presente del pasado. Específicamente, el pasado subjuntivo reveló la katharsis en la deliberación, al mostrar cómo la culpa, la vergüenza o el odio no permitieron alentar valoraciones correctas de la vida buena y digna. Estos juicios corresponden a evaluaciones sobre objetos, situaciones o personas que poseen asociaciones afectivas anteriores. Según Ahmed (2019), como descripciones de cosas que adquirieron valor porque han estado bajo nuestro cuidado y preocupación

El vínculo entre los juicios de valor y las fuerzas narrativas en el nivel contextual de la configuración de la trama. El momento III tuvo como centralidad la interpretación de las tipologías de acciones valiosas, que correspondieron a promesas en las narrativas biográficas. Los juicios compromisorios corresponden a presuposiciones valorativas eudaimonicas y eudemonicasque dieron credibilidad y confianza al cumplimiento de pactos o acuerdos frente a aspiraciones para preservar la vida buena y digna (Quintero-Mejía, 2019). 


\section{Narrativa 1. ¿Por qué lucho?}

Carlos Alberto3, estudiante de admisión especial, orienta el florecimiento de su plan de vida a luchar por la dignidad de las víctimas históricas del conflicto armado en el departamento de Arauca. Los atributos morales que esperaba cultivar otorgaron valor a la benevolencia, la igualdad y al bienestar subjetivo. Él aspira a contribuir con acciones restaurativas desde las entidades públicas, entre ellas la sede Arauca de la Universidad Nacional de Colombia.

Temo que distintos factores se interpongan en la meta a la que quiero llegar

El estudiante aspira a obtener el título de psicólogo para "intervenir en procesos restauración de víctimas, pero siguen presentes grupos al margen de la ley" (M, E, P, 21, NB1, 66). La primera parte de esta presuposición muestra un juicio de valor compasivo ante las víctimas del conflicto armado, que requieren acciones de justicia restaurativa porque han sido vulnerados sus derechos fundamentales. La segunda parte expresa el miedo justificado con los juicios de valor que destacan la presencia de grupos al margen como obstáculo para la intervención psicológica. Estos temores invadieron la conciencia intencional del estudiante durante la deliberación moral, haciendo emerger otros juicios prácticos en dos estructuras temporales: pasado del presente y presente del presente. En pasado del presente, el estudiante expresó temor por "el fallecimiento de un ser querido" (M, E, P, 21, NB1, 38). Esta primera presuposición tiene una elevada valoración en su plan de vida, por ser una amenaza contingente a bienes sociales, que forman parte de sus condiciones disposicionales como sobreviviente del conflicto armado en su comunidad.

\footnotetext{
${ }^{3}$ Nombre ficticio.
} 
En tiempo presente del presente siente miedo por "lo que pueda pasar con la universidad” (M, E, P, 21, NB1, 43). Esta segunda presuposición, tiene como contexto histórico el paro nacional universitario llevado a cabo entre octubre y diciembre de 2018. El estudiante sintió miedo social "debido a la condición socioeconómica de mí familia, no aspiraba a acceder a la educación superior” (M, E, P, 21, NB1, 4). Su única opción ha sido la educación pública, en la medida en que no contaría con recursos suficientes: "en el hipotético y trágico caso de que las políticas frente a la universidad pública cambien abruptamente para mal” (M, E, P, 21, NB1, 45).

La emoción del miedo, en su plan de vida, conduce a otros juicios de valor en tiempo presente del presente (Ricoeur, 2004). El estudiante señala con preocupación que continúa la violencia en su territorio, estigmatizado como "zona roja” (M, E, P, 21, NB1, 25). El narra cómo continúa la emergencia humanitaria debido a la presencia de grupos al margen de la ley, y la inmigración de quienes han cruzado la frontera a través del rio Orinoco. Estas presuposiciones valorativas muestran riesgos que podrían impedir su aspiración a contribuir con la justicia restaurativa en su comunidad de origen.

\section{Miedo a hablar al público y a interactuar con otras personas}

En su deliberación el estudiante expuso dificultades al inicio de la segunda etapa del programa Peama, las cuales se prolongaron a lo "largo de los dos primeros semestres en Bogotá" (M, E, P, 21, NB1, 56). Desde "el principio" (M, E, P, 21, NB1, 51) se convirtió en toda una proeza, lo "que para algunas personas puede llegar a ser algo común, del día a día” (M, E, P, 21, NB1, 51): interactuar y socializar con otros. Recuerda que su experiencia de movilidad a la sede Bogotá estuvo dominada por la rutina, según él, "nada ocurría en mi vida" (M, E, P, 21, NB1, 55). Y sobre todo, le producía mucha 
dificultad establecer vínculos "emocionales con los demás" (M, E, P, 21, $\mathrm{NB} 1,52)$. Cuando esta situación alcanzó un límite intolerable, decidió dar un giro en su vida: aprendió a interactuar y abrirse a los demás. Esto lo logró cuando aprendió a valorar a los demás como bienes relacionales, cuando "te sirven de apoyo para no decaer" (M, E, P, 21, NB1, 41).

Las anteriores proposiciones valorativas muestran los juicios retrospectivos que revelaron argumentos terapéuticos que transformaron creencias negativas hacia sí mismo en su proceso de inserción a la vida universitaria. Primero, sintió apego intenso por el aislamiento y la dificultad en la comunicación. Segundo, observó con preocupación que esto le producía sufrimiento y le afectaba su rendimiento académico. Tercero, decidió cambiar las creencias que le impidieron establecer lazos emocionales, por juicios morales de preocupación de genuina por los demás. Finalmente, descubre la alegría de poder interactuar con otras personas, sentir beneplácito por sus logros o temor porque se vean amenazados. Estos cambios contribuyeron a mejorar su bienestar subjetivo y el rendimiento académico.

Aprender a interactuar: promesa para “ayudar a las personas que me vieron crecer"

Esta promesa adquiere fuerza narrativa como un juicio de valor compromisorio: ser capaz de vincularse con otras personas con amistad y sentido de justicia. La promesa de interactuar y socializar con otros se convierte en obligación moral para "socorrer a otras personas" (M, E, P, 21, NB1, 67). Si el estudiante desea intervenir con víctimas del conflicto armado, debe cultivar el equilibrio psicológico como symphonein. Es decir, alcanzar la armonía personal para cumplir la promesa de ayudar a los demás. 
El plan de vida “¿Por qué lucho?” muestra el significado que tiene para un estudiante del departamento de Arauca acceder a la experiencia universitaria, optando por estudiar psicología, y proyectar su horizonte de graduación hacia el bienestar de las víctimas de su comunidad. En su deliberación se muestra el choque entre la compasión y el miedo que se extendió a otras dimensiones de su experiencia estudiantil. Los juicios de valor que acompañaron la deliberación de Carlos Alberto mostraron el compromiso para desarrollar por medio de su profesión capacidades centrales como la afiliación, el control del entorno, y el equilibrio emocional.

\section{Narrativa 2. Encontrando una vida buena}

Diana Carolina4 tituló su relato encontrando una vida buena, porque llevó a cabo un ejercicio terapéutico sobre conflictos morales entre bienes vulnerables para alcanzar sus aspiraciones, lo cual la ha conducido a: "replantear poco a poco que debo hacer para encaminarme en su alcance" (F, R, AE, 23, NB2, 138).

\section{Mi familia es vulnerable y existe miedo entre nosotros}

La estudiante tiene como aspiración central contribuir al bienestar de la familia, buscando obtener mejores calificaciones laborales para "salir adelante" (F, R, AE, 23, NB2, 41). El ingreso a la Universidad Nacional de Colombia consolida su plan de vida para alcanzar "un mejor futuro, que ya podía ser más tangible" (F, R, AE, 23, NB2, 48). En este momento, se encuentra trabajando en la Universidad y fuera de ella, para disminuir la carga económica de su padre, lo cual ha redundado en "una mejora en nuestra calidad de vida" (F, R, AE, 23, NB2, 48).

\footnotetext{
${ }^{4}$ Nombre ficticio.
} 
Diana Carolina se ve a sí misma como una heroína trágica, que lucha para superar el umbral mínimo de capacidades centrales en hogar porque su madre y hermano padecen cervicalgia5.Esta enfermedad ha convertido su familia en vulnerable debido a sus consecuencias crónicas e incapacitantes para ambos. Sin embargo, ella no puede evitar sentir conflicto moral entre el bienestar propio y el de su familia, y espera superar el miedo para proveer virtudes de cuidado a sus seres queridos.

\section{Me siento culpable por no haber estudiado Medicina}

El miedo lleva a Diana Carolina a sentir culpa por estudiar administración de empresas. En sus palabras: "la culpa ha afectado mi plan de vida porque estoy en un constante dilema moral de pensar si hice lo correcto, y considero que me falto valentía para hacer las cosas" (F, R, AE, 23, NB2, 103). Sus reflexiones dan rienda suelta a la katharsis en el presentepasado subjuntivo. Por una parte, señala que, si bien en un principio había escogido estudiar Medicina, cambió de opinión al imaginarse cómo podría ser su vida: "al estar lejos de mi familia, por ejemplo, haciendo un rural" ( $F, R, A E, 23, N B 2,56$ ), porque creía que podía ocurrir algo trágico cuando ella no se encontrara presente. Por otra, se recrimina por no haber perseverado en su interés por estudiar Medicina, ya que "ofrecía un ambiente más práctico y con mayor conocimiento sobre las enfermedades" (F, R, AE, 23, NB2, 100). Con este conocimiento, ella cree que hubiera podido "contribuir a mejorar la calidad de vida de los dos" (F, R, AE, 23, NB2, 104).

\section{Cuidado y cooperación: promesas para arropar la familia}

La estudiante otorga fuerza narrativa al cuidado y la cooperación como promesas que le otorgan equilibrio emocional, para evitar que el miedo se

\footnotetext{
${ }^{5}$ Cervicalgia, dolor agudo en vértebras cervicales que produce alteración neuromuscular reduciendo la actividad física.
}

Cuadernos de Filosofía Latinoamericana ISSN: 0120-8462 | e-ISSN: 2500-5375 | DOI: https://doi.org/10.15332/25005375 Vol. 42 N. 0124 | enero-junio de 2021 
apodere de ella y afecte el bienestar de su hogar. Diana Carolina convierte la cooperación con su familia y el cuidado a su madre y hermano en objetos felices. Para Sara Ahmed (2019), a ciertos objetos "se les atribuye felicidad porque circulan como bienes sociales antes que la suerte los ponga adelante, esto explica que nos pongamos antes que ellos" (p. 71).

Según esta autora los objetos felices se convierten en causalidad anticipatoria como promesas para una vida buena.

Además, la promesa de cuidado tiene como juicios de valor presuposiciones valorativas como brindar apoyo emocional, tranquilidad y evitar que el miedo afecte el estado de ánimo de la familia. Por ello, se compromete en la búsqueda de nuevas oportunidades de cuidado en el tiempo de la espera para compensar la afectación de capacidades centrales. La acción de cooperación da cuenta de presuposiciones valorativas justas que disponen a la estudiante a una economía moral: mantener una red de apoyo permanente para disminuir el padecimiento del hermano menor.

Promesa de gratitud: retribuir lo que la universidad me ha permitido $y$ me permitirá ser

La estudiante considera "deber moral" (F, R, AE, 23, NB2, 110) participar en actividades de movilización y protesta en el paro nacional de 2018. Ella otorga fuerza narrativa simbólica a la Universidad Nacional de Colombia como espacio de acciones colectivas de resistencia y conciencia política en el país. La alta valoración de la experiencia universitaria tiene como un juicio de valor la reciprocidad para "poder retribuir lo que la universidad me ha permitido y me permitirá ser" (F, R, AE, 23, NB2, 111). Las acciones de resistencia mediante la participación política y el aplazamiento del periodo académico materializan la promesa de que las luchas estudiantiles contribuirán a resolver la crisis en que se encuentra la educación pública, 
para retribuir lo que la universidad pública ha representado para muchos estudiantes de recursos limitados como ella.

Es posible afirmar que el sustrato emocional de la deliberación práctica de Diana Carolina produjo unos juicios de valor en tres temporalidades. Primero, emergió a la superficie el juicio moral de apego intenso hacia su madre y hermano en el presente-presente como prosphatom ${ }^{6}$. Segundo, ella retorna al pasado subjuntivo del presente por medio de la culpa para recriminarse por elegir Administración de Empresas y no esforzarse por alcanzar el puntaje para Medicina. Desde este tiempo subjuntivo, el miedo la orienta al presente-futuro de preocupación dolorosa por el diagnóstico de cervicalgia. Las promesas de cooperación y cuidado contribuyen a restaurar el equilibrio emocional de Diana Carolina para proyectar la salud como un objeto feliz (Ahmed, 2019). También, valora la participación política como aprendizaje valioso para la experiencia estudiantil. Este aprendizaje ha contribuido a "una mayor conciencia sobre su rol como estudiante para ser una solución" (F, R, AE, 23, NB2, 135), porque ofrece una perspectiva realista y critica frente a los problemas de la sociedad colombiana.

\section{Narrativa 3. Crecí creyendo que no tenía nada que ofrecer a los demás}

Emilio Armando7 es estudiante de la carrera de Farmacia. Su narrativa biográfica es un ejercicio terapéutico doloroso al creer que no era una persona digna de una vida bien vivida. Inicia su deliberación afirmando que a sus 27 años jamás se había interrogado sobre el significado de la vida buena ${ }^{8}$ como vida floreciente compartida con otros.

${ }^{6}$ Concepto de Crisipo de Solos citado en Nussbaum (2012).

7 Nombre ficticio

8 Énfasis por el estudiante.

Cuadernos de Filosofía Latinoamericana ISSN: 0120-8462 | e-ISSN: 2500-5375 | DOI: https://doi.org/10.15332/25005375 


\section{Estudiar para progresar económicamente}

El estudiante afirma que los juicios aspiracionales de su plan de vida han estado orientados al progreso económico como horizonte de graduación. Su relación con el conocimiento matemático y científico ha sido instrumental, es decir, para él estudiar Farmacia es solo un medio para conseguir mejores condiciones económicas para el sostenimiento de su madre y tres hermanos.

Mi conflicto ha sido poder entender y actuar para cambiar mi forma de ser

El estudiante menciona como situación de vulnerabilidad, su dificultad para entablar relaciones con personas por fuera de su círculo social en el presente-pasado. Según él, "esta situación lo ha marginado de oportunidades en el campo académico que más adelante pueden ser claves en el campo laboral” ( $M, R, F, 27, N_{3}, 40$ ). De ahí que, contemple que un cambio en sus relaciones interpersonales contribuirá a mejorar su vida buena para emprender proyectos colectivos en el presente-futuro. Relacionarse con otras personas ha representado un conflicto emocional que enuncia con dos presuposiciones con valores opuestos. Por un parte, se siente culpable debido a la falta de interés por los demás, pero por otra, subestima la interacción con sus pares en la experiencia estudiantil. Esta situación lo ha excluido de oportunidades académicas y laborales.

A partir de las consecuencias no deseadas de este acontecimiento, el estudiante reflexiona sobre las causas de su falta de capacidad afiliativa. Para ello lleva a cabo juicios reconstructivos en dos temporalidades del presente-pasado. Primero, se remonta a la experiencia estudiantil mostrando como su falta de interés en las demás, tenía como origen el maltrato recibido en infancia. Segundo, al recordar este acontecimiento, el estudiante revela argumentos terapéuticos reconstructivos para liberarse 
del sufrimiento vivido. Esto contribuye a delinear juicios compromisorios para expandir su círculo social hacia capacidades afiliativas para ganar control de su entorno.

Promesa: cambiar para ser exitoso en cada aspecto de la vida Los argumentos terapéuticos produjeron cambios en los juicios morales sobre las relaciones interpersonales. Emilio Armando reconoce que sus emociones lo han cambiado: "me siento mucho mejor y la ansiedad ha ido disminuyendo poco a poco" (M, R, F, 27, NB3, 73). La promesa de mejorar las relaciones con los demás, revela que el estudiante persigue un bien social, que si bien es vulnerable, también lo puede conducir a alcanzar la excelencia humana. Este fin se logra cuando las relaciones con los demás se convierten en fines en sí mismos, más allá de las ventajas comparativas que se pueda obtener de ellas. Este giro hacia la vida con otros, consiste "en hablar con compañeros de la carrera no solo de la academia, sino de otras cosas de la vida" (M, R, F, 27, NB3, 76).

En la narrativa 3, las fuerzas narrativas emocionales muestran acciones válidas para mejorar la interacción con otros. Estas fuerzas surgieron de la katharsis purificadora de sentimientos dolorosos vividos en la infancia. No obstante, superar el miedo y la ansiedad implica un ordenamiento ascendente de acciones válidas para alcanzar la salud ética. El avance en su capacidad afiliativa, no está exento de dificultades porque debe superar su timidez, debido al miedo inconsciente inculcado con malos tratos, que produjeron vergüenza y rechazo a interactuar con otros.

\section{Discusión y conclusiones}

La emoción del miedo fue una condición constitutiva de los juicios aspiracionales en tres tramas de los planes de vida buena y digna, debido a las condiciones disposicionales que representaron una amenaza para la 
estabilidad familiar o la movilidad en una comunidad. Porque el miedo surgió como una condición suficiente al mostrar afectaciones en la frontera entre el yo y el otro. Por ejemplo, hablar en público, relacionarse con personas o con lugares desconocidos. En todos los casos, esta emoción representó una amenaza a bienes vulnerables en diferentes temporalidades de la experiencia estudiantil: desde el presente-pasado, al presente-pasado, y a partir de este, al presente-futuro como un horizonte de graduación. Veamos a continuación sus movimientos en cada trama narrativa:

En la narrativa 2, la estudiante sintió miedo porque el empeoramiento de la salud de su hermano cambió las aspiraciones de su plan de vida buena y digna. Porque esta enfermedad tenía antecedentes dolorosos en su madre. Esta situación afectó gravemente la dinámica familiar y la llevó a orientar su plan de vida para contribuir a mejorar la salud de su hermano. Al unísono, sintió culpa por no haber podido ingresar a la carrera de Medicina. Para esta estudiante el ingreso a una facultad de salud le hubiese permitido contar con conocimientos científicos para tratar a tiempo los síntomas de su hermano. Los anteriores juicios de valor fueron una condición necesaria para la emoción del miedo, porque crearon una intensa conciencia intencional de los objetos vulnerables que provienen de condiciones externas que lo permiten o lo impiden.

En la narrativa 1, la emoción del miedo estuvo vinculada a condiciones externas por la presencia histórica de actores armados ilegales en la comunidad de origen del estudiante en el departamento de Arauca. Al respecto, Sara Ahmed develó que las políticas del miedo en los territorios expanden la movilidad de unas personas, en detrimento de otras otras ${ }^{9}$

\footnotetext{
9 Para esta autora el estigma y la exclusión convierten a las personas vulnerables en otras otras, por doble efecto metonímico: ser deshumanizadas y despojadas de derechos.
} 
deshumanizadas y despojadas de derechos fundamentales. Este estudiante, junto con su familia, sobrevivió en medio de peligros potenciales, utilizó la evasión o la huida para preservar la vida. Según Ahmed (2015), el miedo instala la subjetividad en el orden de lo reprimido al intensificar la ansiedad y los pensamientos negativos hacia situaciones desconocidas. Esta pegajosidad del miedo lleva a sentir desconfianza de las personas desconocidas y crea distancias psicológicas hacia ellas. Por ello, cuando inició su segunda etapa del programa Peama en la sede Bogotá, sintió temor de hablar en público y evitó el contacto con otras personas.

En la narrativa 3, el miedo fue el resultado de complejas reflexiones sobre consecuencias no deseadas en el plan de vida. El temor a sentirse rechazado impidió al estudiante ampliar su círculo social en la experiencia universitaria. La deliberación lo llevó a remover creencias erróneas sobre sí mismo, inculcadas a través de la humillación y la vergüenza en su socialización primaria. En este caso, como en la narrativa 2, los juicios reconstructivos sobre el miedo condujeron a actitudes pasivas y creencias erróneas sobre la vida con otros. Es decir, no permitieron "tranquilas aprehensiones y estipulaciones de la razón” (Nussbaum, 2012, p. 456). Al mismo tiempo, la compasión como emoción moral otorgó profundidad, estabilidad y afiliación a las aspiraciones de vida buena y digna, las cuales, si bien partieron del bienestar familiar, se proyectaron a bienes externos para la movilidad social. Este empeño se convirtió en un fin en sí mismo con atributos como la benevolencia, la reciprocidad y el respeto. La benevolencia, como sentimiento que lo acompañan para hacer bien a los demás. La reciprocidad con la familia, buscando mejorar los ingresos económicos y servir de apoyo emocional. Y el respeto, en cuanto a la independencia en la toma de decisiones para realizar acciones valiosas en la vida con y para otros. 
La figura materna fue una fuente de reciprocidad intersubjetiva para los tres estudiantes, al contribuir con generosidad al soporte económico y afectivo para el desarrollo de capacidades combinadas. No obstante, la figura paterna fue objeto de sentimientos opuestos en la vida familiar. En la narrativa 2, la estudiante reconoce el rol amoroso y generoso de su padre en el espacio doméstico, lo cual sirvió de emulación profesional para ella. En la narrativa 3, el padre produjo daño moral debido al maltrato y el egoísmo. La decepción, el odio y el desprecio al padre produjeron daños en el bienestar personal y afectaron el rendimiento académico. Y en la narrativa 1, no se mencionó la figura paterna.

De acuerdo a lo anterior, la interpretación del carácter intencional de las emociones en planes de vida permitió mostrar cómo el miedo y la compasión orientaron aspiraciones hacia objetos vulnerables en temporalidades y espacialidades en el devenir de tres jóvenes universitarios. Estas emociones contribuyeron a reflexiones complejas que vincularon creencias sobre las condiciones externas e internas para el florecimiento humano en la experiencia estudiantil.

Además, estos estudiantes llevaron a cabo un ejercicio virtuoso al mostrar los juicios compromisorios para el bien propio (florecimiento personal) y creencias hacia el bien común (justicia). Para Nussbaum (2012) el compromiso es una manifestación de sabiduría práctica, porque permite acciones válidas y corrige creencias para acercarse a la verdad. Especialmente, las promesas tuvieron un valor eudemónico, es decir, atribuyeron "felicidad", porque según Ahmed (2019) "circularon como bienes sociales incluso antes que la suerte los ponga adelante, esto explica que nos pongamos antes que ellos en primer lugar” (Ahmed, 2019, p. 71). Las narrativas1 “¿Por qué lucho?” y 2 "Encontrando una vida buena” revelaron los juicios compromisorios que vincularon el florecimiento 
personal con el bien común. En el primer caso, la promesa de intervenir en procesos de restauración de víctimas tuvo como condición interna necesaria aprender a interactuar y socializar con otras personas. Esta condición selló el pacto moral con la condición externa de socorrer a quienes fueron afectados por el conflicto armado. En el segundo caso, se enunciaron pactos de cuidado y cooperación como garantía para preservar la vida digna en su familia. Por una parte, mantener la cooperación económica con su padre, para disminuir el sufrimiento por la enfermedad de su madre y hermano, y, por otra, el cuidado para brindar un soporte emocional positivo en estas situaciones trágicas.

En la narrativa 3 "Crecí creyendo que no tenía nada que ofrecer a los demás”, el estudiante adoptó como compromiso mejorar sus relaciones, más allá de los beneficios inmediatos que pueda obtener de ellas. Este pacto como condición interna para obtener bienestar psicológico, lo condujo a un tránsito vital doble: por una parte, del utilitarismo al florecimiento humano, y por otra, superar el auto rechazo para poder ofrecerle algo bueno a los demás. En las tres tramas narrativas, las promesas contribuyeron a revisar las creencias que hicieron girar el miedo a perder objetos vulnerables, y ordenar compromisos para preservar la vida buena y digna. El equilibrio emocional fue una condición interna necesaria para el logro de sus fines, al otorgar sus sentimientos de confianza y satisfacción para convertir en humanamente posibles sus planes de vida.

Por último, es importante destacar que estos jóvenes otorgaron una fuerza narrativa simbólica a la Universidad Nacional de Colombia porque les ofreció la oportunidad de acceder a la educación superior. Específicamente, en las narrativas 2 y 3 , se expresaron exigencias de mayor justicia social para la educación superior pública y un respaldo de 
los paros estudiantiles por un mayor presupuesto para alcanzar mayor equidad futuros jóvenes,

Los hallazgos expuestos en este artículo justifican vincular las emociones al razonamiento práctico sobre los planes de vida a partir de los aportes de Martha C. Nussbaum (2004). Sus desarrollos en el liberalismo filosófico proporcionan argumentaciones contundentes para cuestionar la orientación instrumental de los proyectos de vida de jóvenes, lo cual significa según Cabrera (2015) "saber cómo organizar los estudios universitarios para que aquello que hoy es destino, se transforme en opción” (p. 249). Así esta investigación demuestra cómo cada estudiante examinó el carácter moral de objetivos y proyectos en los ámbitos familiar y comunitario. Para lo cual, es necesario el autoexamen de las capacidades para aprovechar mejor las oportunidades. Para esta indagación ética se proponen las emociones como reveladores de criterios morales para una vida digna de ser vivida. Por último, la Catedra Emociones Morales y Políticas ofrece un espacio pedagógico de identificación empática, que posibilita un escrutinio público de conflictos prácticos y trágicos para proyectar la vida con y para otros desde la experiencia universitaria.

\section{Referencias}

Ahmed, S. (2015). La política cultural de las emociones. Universidad Autónoma de México.

Ahmed, S. (2019). La promesa de la Felicidad. Caja negra editora.

Appiah, K. A. (2007). La ética de la identidad. Katz.

Aristóteles. (1948). El arte poética (J. Goya y Munìan, trad.). Edición Austral.

Aristóteles. (1985). Ética a Nicómaco (J. Pallí Bonet, trad.). Gredos.

Cuadernos de Filosofía Latinoamericana

ISSN: 0120-8462 | e-ISSN: 2500-5375 | DOI: https://doi.org/10.15332/25005375

Vol. 42 N.o 124 | enero-junio de 2021 
Cabrera, J. (2015). Carta abierta a los jóvenes estudiantes de filosofía frente a una decisión sería. ¿Qué prefieres ser, un gran comentador o un pequeño filósofo? Cuadernos de Filosofía Latinoamericana, 36(112), 343-353. https://revistas.usantotomas.edu.co/index.php/cfla/article/view/2404/2354

Carli, S. (2012). La experiencia universitaria en la universidad pública. El estudiante universitario. Siglo XXI editores.

Heyd, D. y Miller, F. G. (2010). Life plans: do they give meaning to our lives? The monist, 93(1), 17-37. https://www.jstor.org/stable/41419195

Mill, J. S. (2008). Sobre la libertad. Fondo de Cultura Económica.

Nussbaum, M. C. (2002). Las mujeres y el desarrollo humano. El enfoque de las capacidades. Herder.

Nussbaum, M. C. (2004). La fragilidad del bien. Fortuna y ética en la tragedia y la filosofía griega. La balsa de la medusa.

Nussbaum, M. C. (2012). La terapia del deseo. Teoría y práctica de la ética helenística. Paidós.

Nussbaum, M. C. (2014). Sin fines de lucro. Porque la democracia necesita de las humanidades. Katz.

Nussbaum, M. C. (2018). Paisajes del pensamiento. La inteligencia de las emociones. Magnum.

Pinedo, I. A. y Yáñez, J. (2018). Las emociones: una breve historia en su marco filosófico y cultural en la Antigüedad. Cuadernos de Filosofía Latinoamericana, 39(119), 1345. https://doi.org/10.15332/25005375.5049

Quintero-Mejía, M. (2019). Usos de las narrativas, epistemologías y metodologías. Aportes para la investigación. Centro Editorial Universidad Distrital "Francisco José de Caldas".

Ricoeur, P. (2004). Tiempo y narración I. La configuración del tiempo en el relato histórico. Siglo XXI editores.

Rawls, J. (1995). Teoría de la justicia (2 ed.). Fondo de Cultura Económica.

Silver, J. (2013). Narrative Psychology. En C. Willig (Ed.), Introducing qualitative research in psychology (3 ed.; pp. 421-458). Open University Press. 